\title{
Therapeutic Potential of Plant Phenolics for the Management of Diabetic Retinopathy
}

\author{
Nancy S. Pandita ${ }^{*}$ and Ashlesha S. Vaidya
}

School of Science, SVKM's Narsee Monjee Institute of Management Studies (Deemed-to-be University), Vile Parle (West), Mumbai-400056, India

\begin{abstract}
Diabetes is a systemic disease affecting a large proportion of the population worldwide. Hyperglycemia, the major factor responsible for its development, is known to cause both microvascular and macrovascular complications if not controlled in time. Retinopathy is one such microvascular complication of the eye and has been studied extensively. There are biochemical pathways that lead to its progression and are common to other complications, viz. the formation of advanced glycation end products, the activation of protein kinase $\mathrm{C}$, increase in oxidative stress and the polyol pathway. Though there are standard treatments available to manage diabetic retinopathy, there remains a need to explore herbal medicine as an alternative for its treatment. Many herbal preparations alleviating hyperglycemia that are used to treat diabetes or have insulin sensitizing effects are available in the market. These may help managing diabetic retinopathy, too. Many plants are known to produce inhibitors of advanced glycation end products, the aldose reductase (polyol) pathway, and protein kinase $\mathrm{C}(\mathrm{PKC})$. Hence, there is a necessity to evaluate the potential of these plants, focussing on individual phytoconstituents like phenolic compounds.
\end{abstract}

Keywords: Advanced glycation end products, aldose reductase, diabetes, diabetic retinopathy, insulin, herbal, oxidative stress, phenolics, protein kinase C.

\section{INTRODUCTION}

Diabetes comprises of a group of metabolic disorders caused due to insulin deficiency (Type 1 diabetes) or its inaction (Type 2 diabetes) and is characterized by chronic hyperglycemia. Such a pathological state often leads to further aggravation of problems related to other organs, viz. the eyes, kidneys, heart, nerves, etc. The autoimmune destruction of the beta cells of the pancreas leads to deficient insulin action and abnormalities that result in eventual resistance to insulin. Hence, there is a reduced tissue response to insulin [1].

The microvascular complications of diabetes include diabetic retinopathy, neuropathy, and nephropathy, and cardiomyopathy. In the 1990s, the Diabetes Control and Complications Trial (DCCT) and the United Kingdom Prospective Diabetes Study (UKPDS), independently showed that proper control of hyperglycemia can limit the progression of such complications in both type 1 and type 2 diabetes [2, 3]. Hence, diabetes becomes a crucial determinant of blindness, late-stage renal disease and a variety of debilitating neuropathies [4]. It is also associated with macrovascular disease affecting arteries supplying blood to the heart, brain and lower extremities. Diabetics have a higher risk of myocardial infarction, stroke and limb amputation, and very slow wound healing [5].

\footnotetext{
*Address correspondence to this author at the School of Science, SVKM's Narsee Monjee Institute of Management Studies (Deemed-to-be University), Bhaidas Building, 3rd Floor, Bhakti Vedanta Swami Marg, Vile Parle (West), Mumbai - 400056, India; Tel: 91 9967471319;

Fax: 91-22-26114512; E-mail: nancy.pandita@nmims.edu
}

Diabetic retinopathy (DR), a disease of the eye, is the cause of blindness for approximately $4.8 \%$ of the estimated 37 million blind people in the world [6]. The global prevalence of diabetes is $8.3 \%$, while out of 100 diabetic patients, $34.6 \%$ are likely to develop DR. In India, diabetes shows a prevalence of $8.37 \%$ out of which $18 \%$ of diabetics are likely to develop DR [7-9].

Diabetic retinopathy is classified generally as non proliferative and proliferative, though, in most cases, nonproliferative DR progresses to proliferative DR. The non proliferative type can either develop affecting the macula, or without any pathological change in the macula. (Fig. 1).

Angiogenesis plays an important role in the development of diabetic retinopathy. Neovascularisation is prominent in advanced stages of the disease. Diabetes induces microvascular leakages due to break down of the inner blood-retinal barrier and vascular occlusion which may result in macular edema. Further vascular proliferation can lead to blindness after development of hemorrhages or fibrosis $[11,12]$.

\section{PATHOGENESIS OF DIABETIC RETINOPATHY}

Diabetic Retinopathy can be seen as:

Microaneurysms that are small sac like pouches caused by distension of the walls of the retinal capillaries.

Haemorrhages (internal bleeding) which usually occur within the compact middle layers of the retina.

Hard exudates that are yellow lipid deposits with relatively discrete margins. 


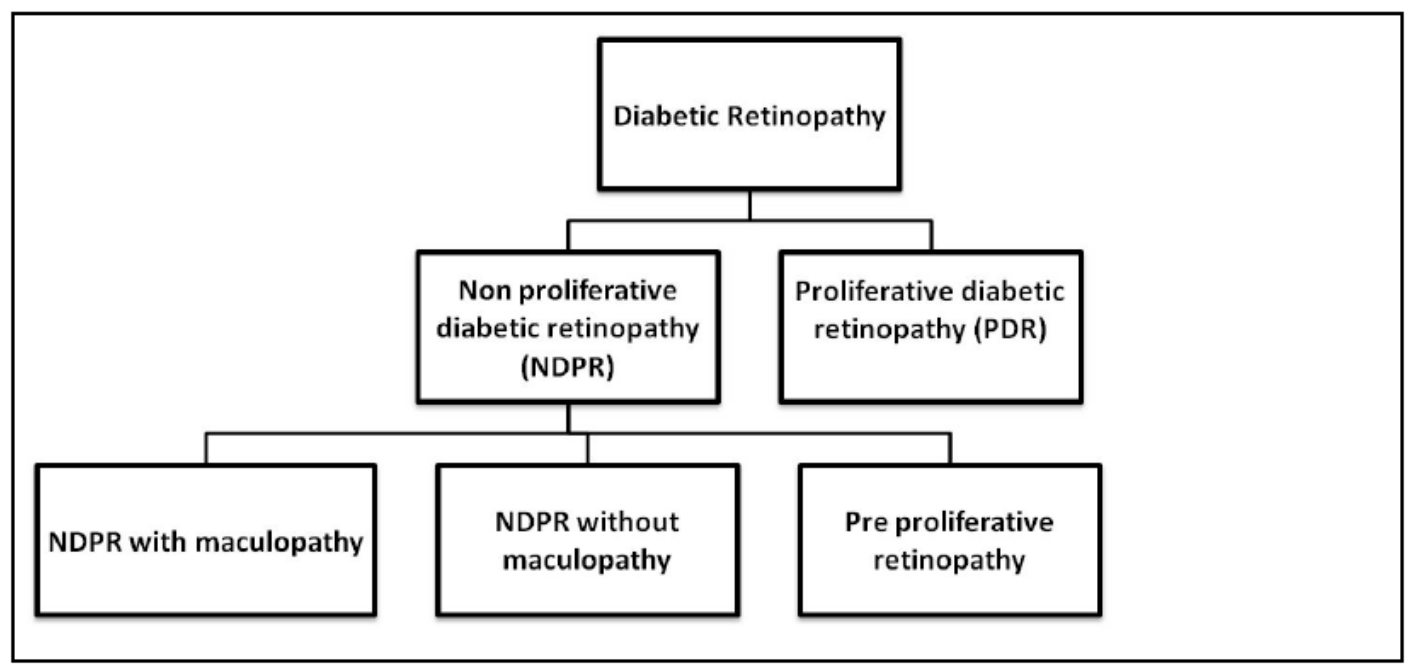

Fig. (1). Classification of diabetic retinopathy [10].

Retinal oedema which appears clinically as greyish areas of retinal thickening, where it may cause marked visual deterioration [13].

\section{Current Treatment Options}

Major advances have been made in understanding the pathogenesis of diabetic retinopathy. Medications for lipid control, glycemic control and tight blood pressure control are effective treatments for DR. From a surgical aspect, pan retinal laser photocoagulation, if performed before severe stages of retinopathy are reached, can reduce vision loss in many cases of retinopathy or macular edema [14]. Vitrectomy, i.e. the removal of the whole or part of the vitreous body, is another option that has shown to reduce visual loss [15].

Corticosteroids like triamcinolone acetonide also improve visual acuity and reduce macular thickness in eyes with macular oedema. Anti-VEGF agents, growth hormone inhibitors, anti platelet agents and PKC inhibitors have also proven to be potential agents to treat $\operatorname{DR}[16,17]$.

However, the standard treatments like triamcinolone acetonide may present with side effects. The invasive techniques like photocoagulation and vitrectomy may reduce loss of vision, but they may be unable to restore lost vision [18]. Herbal medicine can be incorporated in the diabetics from the very beginning as a supplement which can help to avoid the progression of the complications. Also herbals are non invasive in nature.

\section{Target Sites for Treatment}

Many biochemical pathways linked to prolonged hyperglycemia have been implicated in the initiation and progression of diabetic retinopathy (Fig. 2). All retinal cells are affected by hyperglycemic conditions, and it is unlikely that only a single process is responsible for retinal pathophysiology. Hence, establishing the underlying causal mechanisms remains an important research goal [19].

\section{Advanced Glycation End Products (AGES)}

AGEs are known to form on the functional groups of proteins, lipids, and DNA through a number of complicated pathways like nonenzymatic glycation by glucose and reaction with ascorbate, metabolic intermediates, and reactive dicarbonyl intermediates. These reactions modify the structure and function of proteins, and also cause intramolecular and intermolecular cross-linking. AGEs are known to have important effects on retinal vascular cells in vitro, effects that may be mediated through AGE receptors. In in vivo systems, however, the role of AGE formation in diabetic retinopathy continues to remain uncertain. They are known to accumulate in the neural retina and vascular cells of diabetic patients and rats and are associated with pathophysiological changes in the retina and its function [20].

\section{Polyol Pathway}

Aldose reductase (AR), the first enzyme in the polyol pathway, catalyzes the conversion of free D-glucose to sorbitol. Sorbitol penetrates cell membranes poorly and its accumulation in the intracellular compartments has been implicated in the pathogenesis of some of the complications of diabetes. Cataractous lenses from diabetic individuals and individuals with galactosemia contain higher concentrations of sorbitol and in fact have elevated AR activity and immunoreactivity. Even more convincing evidence implicating $\mathrm{AR}$ in the formation of sugar cataracts is the finding that they can be prevented by AR inhibitors $[21,22]$.

\section{Protein Kinase $\mathbf{C}$ and Oxidative Stress}

The activation of the diacylglycerol (DAG)-protein kinase $\mathrm{C}(\mathrm{PKC})$ pathway is associated with many vascular abnormalities in the retinal, renal, neural and cardiovascular tissues in diabetes mellitus. PKC is a group of structurally and functionally related proteins, derived from multiple genes and from alternative splicing of single mRNA transcripts [23, 24]. Its activation increases the production of extracellular matrix and cytokines, enhances contractility, permeability and vascular cell proliferation and neovascularisation via the expression of various growth factors. It also induces the activation of cytosolic phospholipase A2 and inhibits Na- K- ATPase. These events are not only frequently observed in diabetes mellitus but are also involved in the action of vasoactive agents or oxidative stress [25, 26]. 


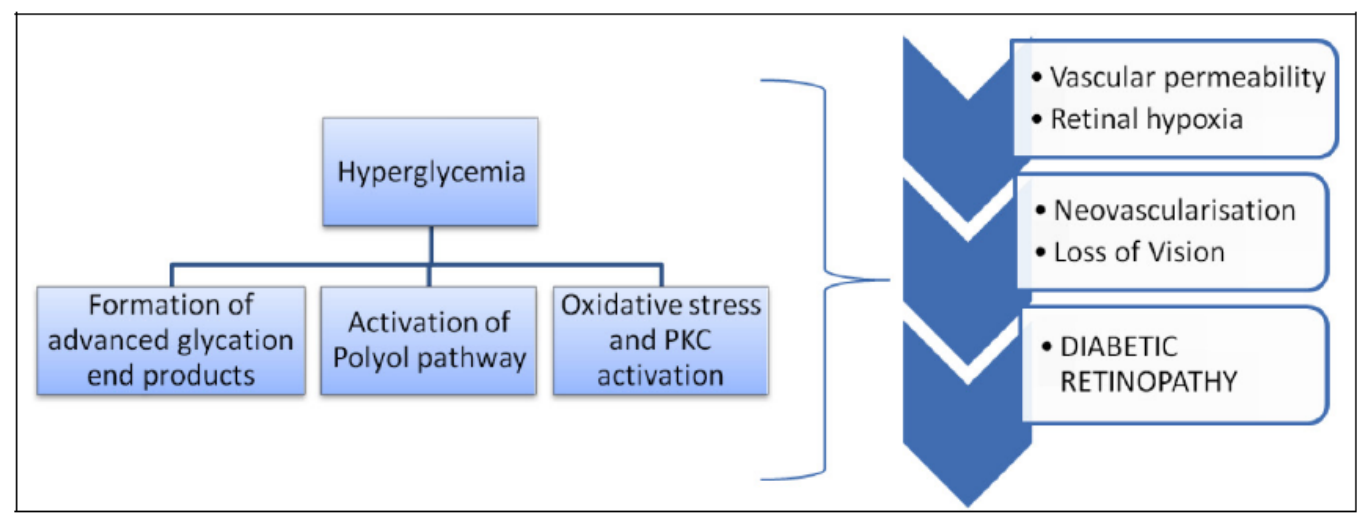

Fig. (2). Progression of diabetic retinopathy.

The retina has high content of polyunsaturated fatty acids and has the highest oxygen uptake and glucose oxidation relative to any other tissue. This phenomenon renders the retina more susceptible to oxidative stress. Animal studies have shown that oxidative stress also contributes to the resistance of retinopathy to reverse even after good glycemic control has been established. This is due to the accumulation of damaged molecules and reactive oxygen species (ROS) [27].

\section{HERBAL APPROACH FOR THE TREATMENT OF DIABETES AND DIABETIC RETINOPATHY}

The prevention, treatment or control of diabetes and its complications without any side effects, still poses a challenge to herbal medicine. The main active constituents of the plants that have shown antidiabetic activity include alkaloids, glycosides, galactomannan gum, polysaccharides, peptidoglycan, hypoglycans, guanidine, steroids, carbohydrates, glycopeptides, terpenoids, amino acids and inorganic ions. These affect various metabolic pathways which disturb the euglycemic state of the human body [28].

Phenolic compounds, another constituent of plants, are secondary metabolites that are derivatives of the pentose phosphate and phenylpropanoid pathways in plants. They are one of the most widely occurring groups of phytochemicals and are of considerable physiological and morphological importance in plants. They exhibit a wide range of medicinal properties such as anti-allergenic, anti-artherogenic, antiinflammatory, antioxidant, cardioprotective and vasodilatory effects. Hence, this review will focus on phenolic compounds and their potential in the management of diabetes and diabetic retinopathy [29].

\section{Plants with Insulin Activity}

Insulin hormone is secreted by the beta cells in the pancreas and plays a central role in regulating the glucose homeostasis. Type 1 diabetes is caused due to the autoimmune destruction of these beta cells resulting in very less or no insulin being produced. Hence, there is no regulation on the uptake of glucose by the cells.

A number of studies have shown plants to have insulin mimetic properties. One such study investigated the role of Malaysian cocoa (Theobroma cacao L.). Cocoa extract (CE) containing 190 - $286 \mathrm{mg}$ total polyphenol per gram extract was administered in three dosages $(1 \%, 2 \%$, and $3 \%)$ to groups of normal and diabetic rats for a period of 4 weeks. Dosages of $1 \%$ and $3 \% \mathrm{CE}$ significantly reduced plasma glucose levels in the diabetic rats. The results of a cell line study also demonstrated that CE significantly increased insulin levels compared to those of the control [30]. Viscum album L. (mistletoe) belonging to family santalaceae has been documented as another plant in the treatment of diabetes. Its aqueous extract $(1-10 \mathrm{mg} / \mathrm{ml})$ had a dose dependent stimulatory effect on insulin secretion by clonal B-cells at $1.1 \mathrm{mM}$ glucose concentrations [31].

In another study, the ethanol extract and each of the hexane, chloroform and ethyl acetate partition fractions of asparagus (Asparagus racemosus Willd., Liliaceae) stimulated insulin secretion in isolated perfused rat pancreas, isolated rat islet cells and clonal b-cells in a concentration dependent manner. They increased intracellular calcium, consistent with the observed suppression of insulin secretory effects under calcium-free conditions, thus proving that the root extracts have wide-ranging stimulatory effects on physiological insulin [32]. An insulin-secreting cell line INS-1 was used to investigate the insulinotropic effects of the crude ethanolic extract of leaves of Bauhinia variegate and its major metabolite (roseoside). Both, the crude extracts and roseoside were shown to increase insulin secretion in a dosedependent manner [33].

Another study of the plant Cortidis rhizoma showed that its constituent berberine reduced triglyceride accumulation by decreased differentiation of fibroblasts to adipocytes. It also increased glucose-stimulated insulin secretion via an enhanced insulin-like growth factor-1 signaling cascade [34]. Brassica nigra L. (Brassicaceae) has been known to possess antidiabetic activity. A study published in 2008 showed that it may possess insulinotropic properties as well. Diabetic rats treated with aqueous extracts of the plant for two months showed a decrease of serum glucose, increase of serum insulin and release of insulin from pancreas in vitro [35].

Cinnamomum zeylanicum Blume (Lauraceae) contains cinnamaldehyde (CND) as an active principle that possesses anti diabetic potential. A study of the same plant demonstrated that in vitro incubation of pancreatic islets with CND enhanced insulin release when compared to glibenclamide. It also increased the glucose uptake through glucose transporter (GLUT4) translocation in peripheral tissues [36]. 
Aqueous extracts of three more plants, i.e. Enicostemma littorale Blume (Gentianaceae), Eriobotrya japonica Lindl. (Rosaceae) and Tabernanhte iboga Baill. (Apocynaceae) in individual studies also showed the potential to induce insulin secretion or release in experimental models [37-39]. Genistein, a soy isoflavone, showed increase in rapid glucosestimulated insulin secretion in insulin-secreting cell lines and mouse pancreatic islets. It directly acts on pancreatic beta cells and further leads to the activation of the cAMP/PKA signaling cascade [40].

\section{Plants with Hypoglycemic or Anti-hyperglycemic Activity}

According to epidemiological studies, glycemia and diabetic complications in type 1 and type 2 diabetes go hand in hand. There is always a prevailing risk of progression of complications if hyperglycemia persists [41]. Therefore, many plants which have been studied for their hypoglycaemic activity may have potential for the management of diabetic retinopathy.

One research group has explored the possible mechanisms of antidiabetic action of two medicinal plants, Ficus racemosa Linn. (Moraceae) bark (FRB) and Morus indica L.( Moraceae) leaves (MI). Studies demonstrated that both the plants showed a decent glucose adsorption capacity and lowered glucose diffusion. They also inhibited enteric carbohydrate hydrolyzing enzymes like $\alpha$-amylase, $\alpha$-glucosidase and sucrase. Apart from these properties, both plants also showed a cholesterol and triglyceride lowering effect [42]. Another study showed that the plant Swertia kouitchensis Franch. (Gentianaceae) and its components xanthone and triterpenoids could decrease the postprandial glucose level by inhibiting the activity of $\alpha$-amylase and $\alpha$-glucosidase. After treated with its extract or gliclazide for 4 weeks, levels of triglycerides, total cholesterol and LDL (low density lipoprotein) levels were decreased while HDL (high density lipoprotein) levels were increased in the diabetic mice. Also, glucokinase (GK) activity increased while glucose-6phosphatase (G6Pase) activity decreased in the liver [43]. GK helps in regulating the carbohydrate metabolism by making amends in metabolism in response to rising or falling levels of glucose. G6Pase hydrolyzes glucose-6phosphate into a phosphate group and free glucose. Hence both the enzymes play a critical role in glucose homeostasis.

A comparative study of 2 plants from Myrtaceae, Cleistocalyx operculatus (Roxb.) Merr. et Perry.(CO) and Psidium guajava L. (guava leaves) using in vivo and in vitro methods demonstrated that the carbohydrate-hydrolysing enzyme inhibitory action and the post prandial blood glucose suppression of the $\mathrm{CO}$ extract was higher than that of the guava leaves extract in both in vivo and in vitro conditions [44].

Ficus amplissima Smith. belonging to family Moraceae (FAB) is another plant whose antidiabetic activity has been studied. Its oral administration led to a significant decrease in blood glucose levels. Compared with glibenclamide, it was shown that the mechanism of action of FAB is much the same. FAB considerably reduced serum triglycerides and total cholesterol in STZ-diabetic rats. It also controlled the increased lipid peroxidation which may be due to the anti- oxidant effect of flavonoids present in it. Apart from lipids, its treatment normalized the total protein content in diabetic rats, indicating its possible potential of treating kidney disorders [45]. Cassia occidentalis L. (Fabaceae), just like several other Cassia species, also has a similar effect of lowering serum lipids, and serum proteins [46]. The flavonoids isolated from the plant Averrhoa carambola (Oxalidaceae) i.e; apigenin-6-C- $\beta$ fucopyranoside and apigenin-6-C- $(2 "-\mathrm{O}-\alpha-$ rhamnopyranosyl)- $\beta$-fucopyranoside were able to increase the glycogen content in soleus muscle of diabetic animals when compared to normal animals. The former compound stimulated glycogen content in the liver as well. This proves that this plant may have potent anti hyperglycemic properties [47].

Two separate studies demonstrated the hypoglycaemic potential of the plant Butea monosperma (Lam.) kuntze (Fabaceae) when tested on alloxan induced diabetic rats. During diabetes, the excess glucose present in the blood reacts with haemoglobin forming glycosylated haemoglobin. Hence, the total haemoglobin level is lowered in alloxan diabetic rats. Methanolic extracts of Butea monosperma leaves lowered the total haemoglobin level in alloxan diabetic rats to almost normal levels. They also led to a decreased total cholesterol level and improved HDL level. Enzymes such as serum glutamate oxaloacetate transaminase (SGOT), serum glutamate pyruvate transaminase (SGPT), super oxide dismutase (SOD), catalase (CAT), and glutathione peroxidise (GPx) are serum enzymes that have physiological functions. In diabetic conditions, their levels tend to fluctuate. While SGPT and SGOT constitute liver enzymes, SOD, CAT and GPx are defense mechanisms against reactive oxygen species. The methanolic extracts of Butea monosperma brought down the SGPT and SGOT levels to normal. The antioxidant enzymes were over expressed in diabetic rats treated with the extracts. This indicates that some major components (flavonoids) in the extract strengthen the anti oxidant defence [48]. Similarly, ethanolic extracts of the flowers of the plant prevented the blood glucose levels from rising significantly after administration of glucose, without causing any hypoglycaemia [49].

Apart from the ones mentioned above, there are several other plants which have reported anti-hyperglycemic activity. Momordica charantia [50], Nervilia plicata [51], Gymnema sylvestre, Ficus religiosa, Eugenia jambolana, Allium sativum, Pterocarpus marcupium, and Ocimum sanctum are a few $[52,53]$. Gymnema sylvestre is known to have high antidiabetic activity. It inhibits elevated serum parameters like blood glucose, cholesterol, triglycerides.

\section{Plants Having Potential for Management of Diabetic Retinopathy}

There are several plants which have been studied as potential agents to target the pathways described above. The following summary attempts to cover the most widely studied among them.

\section{Inhibitors of Advanced Glycation End Product (AGE) Formations}

Non-enzymatic glycosylation of proteins is one of the major causes of diabetic complications, such as retinopathy, 
nephropathy and neuropathy and cardiomyopathy. In one study, flavonoids such as quercetin, apigenin and biochanin A were evaluated for their ability to inhibit the glycosylation of three proteins, ie haemoglobin, insulin and albumin. The results showed that quercetin and apigenin had the highest inhibitory effect on albumin glycosylation, and biochanin A had the strongest inhibitory effect on albumin and insulin glycosylation. Hemoglobin glycosylation was the least inhibited [54].

In another study involving the crude extracts of the roots of the plant Astralagus radix (AR), compounds preventing the formation of carboxymethyllysine (CML) and pentosidine were isolated. Astragalosides significantly inhibited the formation of both CML and pentosidine. This data suggest that $\mathrm{AR}$ and astragalosides may be potential inhibitors of AGEs [55].

Nelumbo nucifera Gaertn. (Nelumbonaceae) is another plant which was studied for its antioxidant and antidiabetic properties uding assays such as 1-diphenyl-2-picrylhydrazyl (DPPH) assay, Trolox equivalent antioxidant capacity (TEAC) assay, total reactive oxygen species (ROS) assay, and advanced glycation endproducts assay. The leaf extracts showed high values for total phenolic content (TPC) and total flavonoid content (TFC). When tested on rats, the ethyl acetate and butanol fractions, with prominent TPC and TFC values, showed significant antioxidant capacity. The ethyl acetate fraction also showed better inhibitory effects in the AGE assay [56].

Cuminum cyminum L. (Apiaceae) and its monoterpene, p-Cymene was investigated for its potential to inhibit the formation of advanced glycation end products. In this study, streptozotocin induced diabetic rats were treated with cymene and its treatment lowered the glycated haemoglobin levels as compared to diabetic control, though there was a slight rise in blood glucose levels. In vitro studies of cymene in a bovine serum albumin system showed that cymene showed a decrease in AGE specific fluorescence comparable to aminoguanidine which is a known AGE inhibitor [57]. Another study tested the polyphenol containing plant Origanum majorana L., Lamiaceae (OM) by both in vivo and in vitro methods. A bovine serum albuminmethylglyoxal system was used and a number of positive results confirmed that the polyphenol content of this plant may be potent as an AGE inhibitor. Firstly, OM extracts were able to inhibit the formation of methylglyoxal derived advanced glycation end-products. They also halted the conversion of dicarbonyl intermediates to advanced glycation end-products [58].

A similar comparative study between green tea and Ilex paraguariensis A. St. Hil. (Aquifoliaceae) was done with the help of in vitro methods taking aminoguanidine as a standard. The study demonstrated that Ilex paraguariensis was much more potent in terms of inhibiting AGEs compared to green tea [59].

Phenolic compounds, thus, have proven that they are one of the most important phytochemicals having major physiological abilities in diabetes. A recent study that evaluated the in vitro AGE inhibiting activity of 17 plants strengthened this fact. All of them boasted of high amounts of total pheno- lic content, which was responsible, as their results suggested, for their antioxidant and AGE inhibiting ability [60].

\section{Inhibitors of Aldose Reductase (Polyol Pathway)}

Since aldose reductase (AR) is a key enzyme known to play important roles in diabetic complications, its inhibitors may serve to be potential agents for the management or treatment of diabetes mellitus.

In a study to demonstrate the effects of the plant Ganoderma applanatum (Ganodermataceae), its methonolic extract was tested for the AR enzyme activity. It was proved that the extract inhibited the enzyme in a concentration dependent manner. The IC50 (half maximal inhibitory concentration) values of the extracts were much higher than those of a standard AR inhibitor. The extracts also lowered the sorbitol accumulation in sciatic nerves [61]. Another plant, Cinnamomum cassia (Lauraceae), was shown to possess the ability to inhibit AR enzyme activity. In this study, fractions of the bark extracts of the plant were purified with the help of silica gel column chromatography and HPLC and the isolates were checked for any AR enzyme inhibitory activity. Among all the purified components ie cinnamaldehyde, cinnamic acid and cinnamyl alcohol, cinnamaldehyde was found to have the highest inhibitory activity when compared to quercetin, which is known to be a potent AR inhibitor [62]. Aqueous extracts of Emblica officinalis Gaertn. (Euphorbiaceae) were tested against aldose reductase enzyme. They inhibited rat lens AR, as well as recombinant human AR. With further investigation, it was found that the hydrolysable tannoids were responsible for the inhibitory activity. The inhibition of AR by Emblica officinalis tannoids was 100 times higher than its aqueous extract and comparable to or better than quercetin [63]. In another study, the plant Hybanthus enneaspermus (L) F. Muell (Violaceae) was checked for its AR inhibitory activity. Different fractions of the plants were prepared in different solvents, viz. pet ether, chloroform, ethyl acetate and water. Among these, the ethyl acetate fraction showed the highest inhibitory activity and the results also showed a very high percentage of total flavonoid and total phenol content. Thus, it can be postulated that the flavonoid content of Hybanthus enneaspermus show potential to be AR inhibitors [64].

Flemingia species (Fabaceae) are known to have potential for treatment of disorders like rheumatism, leucorrhea, menalgia, menopausal syndrome, etc. A study evaluated its antioxidant and antidiabetic properties. Four Flemingia species Flemingia macrophylla (FM), Flemingia prostrata (FP), Flemingia lineate (FL), and Flemingia strobilifera (FS) were studied by comparing them with the chemical compound genistein as a positive control. The IC50 of the extracts of the four Flemingia species increased in the following order: FM $>$ FS $>$ FL $>$ FP. FM had the highest AR inhibitory activity as it surpassed the level of geistein. Among the four species, FM had the highest total phenol content, again pointing towards the fact that phenolic compounds may possess significant AR inhibitory activity [65].

In a different approach to look for AR inhibitors in plants, an extensive library of Rauwolfia serpentina (Apocynaceae) molecules was compiled and screened for AR inhibitory action in a computational manner. Using a molecular 
docking approach, three structures were identified as contenders for probable AR inhibitory activity, ie indobine, indobinine, and 19(S), 20(R)-dihydroperaksine-17, 21-al. The reliability of the procedure was checked by performing docking of AR with 4, 5-Di-O-caffeoylquinic acid, a known potent AR inhibitor. Among the three, the chemical interactions established between indobine and AR binding pocket residues were found to be the most stable. Structural analogs of indobine also were established that may have potential AR inhibitory activity [66].

Another study evaluated finger millet polyphenols (FMP), i.e. plant Eleusine coracana Gaertn. (Poaceae) for their AR inhibiting action. FMP majorly consist of gallic, protocatechuic, p-hydroxy benzoic, pcoumaric, vanillic, syringic, ferulic, and trans-cinnamic acids and quercetin, confirmed by HPLC anlaysis. Apart from p-hydroxy benzoic, vanillic and ferulic acids, all the other phenolic compounds were found to have significant IC50 values, quercetin being the most potent AR inhibitor among them all. Structure function analysis of the compounds showed that phenolic compounds having $\mathrm{OH}$ group at 4 th position were able to have a better aldose reductase inhibitory property [67].

Another example of a phenolic compound as probable potent inhibitors of AR is ellagic acid. Studies have shown that it delays diabetic cataract, a presymptom of retinopathy, and also suppressed sorbitol accumulation in human erythrocytes, rat lens and rat retina under hyperglycemic conditions [68]. Naringin is yet another flavonoid and which reduced the activity of aldose reductase [69].

Other plants known to possess AR inhibitory activity include Manilkara indica (Sapotaceae), Belamcanda chinensis (Iridaceae), Chrysanthemum boreale (Asteraceae), where phenolic acids are the principal components responsible, [70-72] and Coptis japonica (Ranunculaceae), Cuminum cyminum (Apiaceae), where alkaloids and essential oils, respectively, are the major components $[73,74]$.

Some studies have also reported on the effect of plants on the pathophysiology of the diabetic eye. A few of the plants and phytoconstituents have been mentioned below (Table 1).

\section{Antioxidant and PKC Inhibitors}

An imbalance between oxidants and antioxidants caused by excess free radicals in the body leads to oxidative stress. Antioxidants like vitamin A (retinoids), vitamin C (ascorbic acid) and vitamin $\mathrm{E}$ (tocopherols) have proven themselves potent enough to reverse the activation of PKC, by downregulating its activity [83].

An in vitro study was performed to test natural phenolic compounds for their effect on the activity of protein kinase $\mathrm{C}$ (PKC) isolated from irradiated as well as non-irradiated mice. The elevated PKC activity as a result of the irradiation was reduced by curcumin and ellagic acid [84]. Curcumin (Curcuma longa, Zingiberaceae) also showed interference with $\mathrm{PKC}$ regulation and calcium metabolism, thus inhibiting ROS (reactive oxygen species) formation [85]. Additionally, it also inhibited interleukin and vascular endothelial growth factor (VEGF), which are agents promoting the progression of diabetic retinopathy [86].
Table 1. Effects exerted by plants on physiology of eye in diabetic conditions.

\begin{tabular}{|c|c|}
\hline Plant/Phytochemical & Physiological Effect \\
\hline \hline $\begin{array}{c}\text { Salvia miltiorrhiza } \\
\text { (Lamiaceae) }\end{array}$ & $\begin{array}{c}\text { Improves microcirculation, lessens damage to } \\
\text { cell structure [75] }\end{array}$ \\
\hline $\begin{array}{c}\text { Stephania tetrandra } \\
\text { (Menispermaceae) }\end{array}$ & $\begin{array}{c}\text { Helps to block formation of extra blood vessels } \\
\text { (neovascularisation) of retinal capillaries [76] }\end{array}$ \\
\hline $\begin{array}{c}\text { Lycium barbarum } \\
\text { (Solanaceae) }\end{array}$ & $\begin{array}{c}\text { Helps reduce loss of retinal ganglion cells due } \\
\text { to intraocular pressure [77, 78] }\end{array}$ \\
\hline $\begin{array}{c}\text { Gingko biloba } \\
\text { (Ginkgoaceae) }\end{array}$ & $\begin{array}{c}\text { Helped improve retinal capillary blood flow } \\
\text { and improved viscosity of blood and in diabetic } \\
\text { conditions [79] }\end{array}$ \\
\hline Hypericin & $\begin{array}{c}\text { Inhibits retinal neovascularisation and allevi- } \\
\text { ates extracellular signal regulated kinase (ERK) } \\
\text { phosphorylation in ischemic retinas [80] }\end{array}$ \\
\hline Resveratrol & $\begin{array}{c}\text { Helps prevent photoreceptor cell death and } \\
\text { retinal detachment [81] }\end{array}$ \\
\hline Vitamin E & Normalises retinal blood flow [82] \\
\hline
\end{tabular}

Green tea [Camellia sinensis (L.) Kuntze, Theaceae] has been established as a plant having varied physiological effects. It contains a lot of phenolic compounds. In separate studies, the researchers have proved that it can reduce retinal superoxide formation to a significant degree and can scavenge reactive radical species [87-89].

Olive leaves, (Olea europaea L., Oleaceae) consisting of oleuropein, are also an antioxidant option. Oleuropein managed to restore the elevated levels of plasma and erythrocyte malondialdehye (MDA) levels to near normalcy. MDA is a byproduct of lipid peroxodation, and is a marker of oxidative stress [90]. Apart from olive leaves, phenolic compounds from olive mill waste were also tested for their antioxidant capacity. Though they may not have been studied for retinopathy specifically, their positive results of inhibiting the rise of blood glucose levels and keeping the antioxidant enzymes in check surely points to the fact that they are potential antioxidants for retinopathy cases as well [91].

In another study, astaxanthin, a carotenoid, proved to be a potent antioxidant as it was able to reduce the rate of apoptosis of the retinal ganglion cells in diabetic mice. It also attenuated the MDA levels in the retinal tissues [92]. Similar to astaxanthin, alpha lipoic acid also inhibits lipid peroxidation, as shown by another research study [93].

Another plant which increased the activities of antioxidant enzymes like CAT, SOD, etc is Hericium erinaceus (Hericiaceae). It even led to a significant decrease in serum glucose levels and a significant increase in serum insulin [94]. Panax ginseng (Araliaceae) too was found to have antioxidant properties as its component ginsenoside helped restore glutathione and MDA levels in the eye and kidney comparable to those found in the control rats. It could also lower blood glucose and lipid levels in the experimental models [95]. 
Antioxidants, especially flavonoids, thus play an important role in the management of diabetic complications. Flavonoids, are adept at protecting retinal ganglion cells (those which are responsible for vision) from oxidative stress [96]. As diverse as they are, they are even known to block the activity of protein kinase $\mathrm{C}$, though additional studies are still needed to establish their role specifically targeting isoforms of PKC in conditions such as diabetic retinopathy [97]. Two plants that have established their role as inhibitors ok PKC include Tinospora cardifolia (Menispermaceae), and Moringa oleifera (Moringaceae) [98, 99]. There are several plants yet to be studied for their ability to be therapeutic options for diabetic complications, and a few are listed above. To reiterate, phenolic compounds, if isolated and studied for their efficacy, show great promise as lead compounds for the development of drugs or formulations.

In cases such as those of DR, after the evaluation of plants for their anti diabetic potential and their ability to manage DR, special focus should be laid on developing eye drop formulations out of them. One such study has been attempted to do the same by selecting plants like Berberis aristata (stem wood), Berberidaceae; Cassia absus (seed), Fabaceae; Coptis teeta (rhizome), Ranunculaceae and Symplocos racemosa (Symplocaceae) and Azadirachta indica (Meliaceae) and studying the anti inflammatory properties. The results not only pointed out that these plants were effective in reducing inflammation, but also the fact that treating eye disorders using eye drop formulations may be a favourable option [100].

\section{CONCLUSION}

Ayurveda has recognised diabetes as Prameha and Madhumeha, i.e. the rise in the blood sugar levels. Hence, the management of diabetes was well established in those times with the help of plants/natural products. Other diseases were also well treated, and still do, with the help of Ayurveda. Yet, there is a rising trend in the prevalence of diabetes and other complications, today. New drug development strategies have to be implemented for treating the same. The present scenario needs to study the detailed pathways in which the plant derived metabolites can work favourably in treating DR.

A lot of effort also needs to be put in evaluating the potential of single phytoconstituents especially phenolic compounds as they have shown a lot of promise. Also, the above studies can be further evaluated for their safe and effective drug of choice in diabetes and its complications.

ABBREVIATIONS
$\begin{array}{ll}\mathrm{AGES} & =\text { Advanced Glycation End Products } \\ \mathrm{AR} & =\text { Aldose Reductase } \\ \mathrm{CAT} & =\text { Catalase } \\ \mathrm{CE} & =\text { Cocoa Extract } \\ \mathrm{CML} & =\text { Carboxymethyllysine } \\ \mathrm{CND} & =\text { Cinnamaldehyde } \\ \mathrm{CO} & =\text { Cleistocalyx operculatus } \\ \mathrm{DAG} & =\text { Diacylglycerol }\end{array}$
DCCT $=$ Diabetes Control and Complications Trial
DPPH $=1$-Diphenyl-2-Picrylhydrazyl
DR = Diabetic Retinopathy
$\mathrm{FAB}=$ Ficus amplissima Bark
$\mathrm{FL}=$ Flemingia lineate
$\mathrm{FM}=$ Flemingia macrophylla
FMP $=$ Finger Millet Polyphenols
$\mathrm{FP}=$ Flemingia prostrata
FRB $=$ Ficus racemosa Bark
FS $\quad=$ Flemingia strobilifera
G6Pase = Glucose-6-Phosphatase
GK $=$ Glucokinase
GLUT4 = Glucose Transporter
Gpx = Glutathione Peroxidise
$\mathrm{HDL}=$ High Density Lipoprotein
IC50 = Half Maximal Inhibitory Concentration
LDL = Low Density Lipoprotein
MDA $=$ Malondialdehye
MI $=$ Morus indica
$\mathrm{PKC}=$ Protein Kinase $\mathrm{C}$
ROS = Reactive Oxygen Species
SGOT = Serum Glutamate Oxaloacetate Transaminase
SGPT = Serum Glutamate Pyruvate Transaminase
SOD $=$ Super Oxide Dismutase
TEAC $=$ Trolox Equivalent Antioxidant Capacity
$\mathrm{TFC}=$ Total Flavonoid Content
TPC $=$ Total Phenolic Content
UKPDS $=$ United Kingdom Prospective Diabetes Study
VEGF = Vascular Endothelial Growth Factor

\section{CONFLICT OF INTEREST}

The authors confirm that this article content has no conflict of interest.

\section{ACKNOWLEDGEMENTS}

Declared none.

\section{PATIENT'S CONSENT}

Declared none.

\section{REFERENCES}

[1] American Diabetes Association. Diagnosis and classification of Diabetes Mellitus. Diabetes Care, 2012, 3, S64-S69.

[2] The Diabetes Control and Complications Trial Research Group. The effect of intensive treatment of diabetes on the development and progression of long-term complications in insulin-dependent diabetes mellitus. N. Engl. J. Med., 1993, 329(14), 977-986. 
[3] Turner, R. Intensive blood-glucose control with sulphonylureas or insulin compared with conventional treatment and risk of complications in patients with type 2 diabetes (UKPDS 33). Lancet, 1998, 352(9131), 837-853.

[4] Chiarelli, F.; Marcovecchio, M.L. In: The molecular mechanisms underlying diabetic complications, Proceedings of the 7th APPES Biennial Scientific Meeting, Nusa Dua, Bali. November 14-17, 2012; International Journal of Pediatric Endocrinology, 2013.

[5] Fowler, M.J. Microvascular and macrovascular complications of diabetes. Clin. Diabetes, 2008, 26(2), 77-82.

[6] Resnikoff, S.; Pascolini, D.; Etya'ale, D.; Kocur, I.; Pararajasegaram, R.; Pokharel, G.P.; Mariotti, S.P. Global data on visual impairment in the year 2002. Bull. World Health Organ., 2004, 82(11), 844-851.

[7] International Diabetic Federation. IDF Diabetes Atlas, $5^{\text {th }}$ ed, 2011. Available at: http://www.idf.org/sites/default/files/da5/ 5eDiabetesAtlas_2011.pdf [Accessed October 23, 2013].

[8] Yau, J.W.Y.; Rogers, S.L.; Kawasaki, R.; Lamoureux, E.L.; Kowalski, J.W.; Bek, T.; Chen, S.; Dekker, J.M.; Fletcher, A.; Grauslund, J.; Haffner, S.; Hamman, R.F.; Ikram, M.K.; Kayama, T.; Klein, B.E.K.; Klein, R.; Krishnaiah, S.; Mayurasakorn, K.; O’Hare, J.P.; Orchard, T.J.; Porta, M.; Rema, M.; Roy, M.S.; Sharma, T.; Shaw, J.; Taylor, H.; Tielsch, J.M.; Varma, R.; Wang, J.J.; Wang, N.; West, S.; Xu, L.; Yasuda, M.; Zhang, X.; Mitchell, P.; Wong, T.Y. Global prevalence and major risk factors of diabetic retinopathy. Diabetes Care, 2012, 35(3), 556-564.

[9] Raman, R.; Rani, P.K.; Reddi, R.S.; Gnanamoorthy, P.; Uthra, S.; Kumaramanickavel, G.; Sharma, T. Prevalence of diabetic retinopathy in India: Sankara nethralaya diabetic retinopathy epidemiology and molecular genetics, study report 2. Ophthalmology, 2009, 116(2), 311-318.

[10] Balasubramanyam, M.; Rema, M.; Premanand, C. Biochemical and molecular mechanisms of diabetic retinopathy. Curr. Sci., 2002, 83(12), 1506-1514.

[11] Williard, A.L.; Herman, I.M. Vascular Complications and Diabetes: Current therapies and future challenges. J. Opthalmol., 2012, 2012, 1-14.

[12] Lloyd, P.A. The potential role of PKC in diabetic retinopathy and macular edema. Surv. Ophthal., 2002, 47(2), S263-S269

[13] Watkins, P.J. $A B C$ of Diabetes, $5^{\text {th }}$ ed, BMJ Publishing Group, London, 2003.

[14] Yam, J.C.; Kwok, A. Update on the treatment of diabetic retinopathy. Hong Kong Med. J., 2007, 13(1), 46-60.

[15] Comer, G.M.; Ciulla, T.A. Current and future pharmacological intervention for diabetic retinopathy. Expert Open. Emerging drugs, 2005, 10(2), 441-455.

[16] Rosberger, D.F. Diabetic Retinopathy: Current concepts and emerging therapy. Endocrinol. Metab. Clin. N. Am., 2013, 42(4), $721-745$.

[17] Chang, L.K.; Sarraf, D. Current and future approaches in the prevention and treatment of diabetic retinopathy. Clin. Opthalmol., 2008, 2(2), 425-433.

[18] Zhang, H.W.; Zhang, H.; Wan, X.; Li, G; Grant, S.J. Herbal medicine for diabetic retinopathy (Protocol). Cochrane Database of Systematic Reviews, 2009, Issue 3. DOI: 10.1002/14651858.CD007939.

[19] Llyod, P.A. The molecular biology of diabetic retinopathy: opportunities for therapeutic intervention. Adv. Stud. Ophthalmol., 2006, 3(1), 8-12.

[20] Stitt, A.; Gardiner,http://diabetes.diabetesjournals.org/content/ 51/9/2826.long - aff-1 T.A.; Anderson, N.L.; Canning, P.; Frizzell, N.; Duffy, N.; Boyle, C.; Januszewski, A.S.; Chachich, M.; Baynes, J.W.; Thorpe, S.R. The AGE inhibitor pyridoxamine inhibits development of retinopathy in experimental diabetes. Diabetes, 2002, 51(9), 2826-2832.

[21] Vinores, S.A.; Campochiaro, P.A.; Williams, E.H.; May, E.E.; Green, W.R.; Sorenson, R.L. Aldose reductase expression in human diabetic retina and retinal pigment epithelium. Diabetes, 1988, 37(12), 1658-1664.

[22] Brownlee, M. Biochemistry and molecular cell biology of diabetic complications. Nature, 2001, 414(6865), 813-820.

[23] Idris, I. Donnelly, R. Protein kinase C-beta inhibition: a novel therapeutic strategy for diabetic microangiopathy. Diabetes. Vasc. Dis. Res., 2006, 3(3), 172-178.
[24] Donnelly, R.; Idris, I.; Forrester, J.V. Protein kinase C inhibition and diabetic retinopathy: a shot in the dark at translational research. Br. J. Ophthalmol., 2004, 88(1), 145-151.

[25] Meier, M.; King, G.L. Protein kinase C activation and its pharmacological inhibition in vascular disease. Vasc. Med., 2000, 5(3), 173-85.

[26] Tuttle, K.R.; Anderberg, R.J.; Cooney, S.K.; Meek, R.L. Oxidative stress mediates protein kinase $\mathrm{C}$ activation and advanced glycation end product formation in a mesangial cell model of diabetes and high protein diet. Am. J. Nephrol., 2009, 29(3), 171-180.

[27] Kowluru, R.A.; Chan, P. Oxidative stress and diabetic retinopathy. Exp. Diabetes Res., 2007, 2007, 01-12.

[28] Prabhakar, P.K.; Doble, M. A target based therapeutic approach towards diabetes mellitus using medicinal plants. Curr. Diabetes Rev., 2008, 4(4), 291-308.

[29] Balasundram, N.; Sundram, K.; Samman, S. Phenolic compounds in plants and agri-industrial by-products: Antioxidant activity, occurrence, and potential uses. Food Chem., 2006, 99(1), 191-203.

[30] Ruzaidi, A.; AMaleyki, A.; Amin, I.; Nawalyah, A.G.; Muhajir, H.; Pauliena, M.B.S.; Muskinah, M.S. Hypoglycaemic properties of Malaysian cocoa (Theobroma cacao) polyphenols-rich extract. Intl. Food Res. J., 2008, 15(3), 305-312.

[31] Gray, A.M.; Flatt, P.R. Insulin-secreting activity of the traditional antidiabetic plant Viscum album (mistletoe). J. Endocrinol., 1999, 160(3), 409-414.

[32] Hannan, J.M.A.; Marenah, L.; Ali, L.; Rokeya, B.; Flatt, P.R.; Abdel-wahab, Y.H. Insulin secretory actions of extracts of Asparagus racemosus root in perfused pancreas, isolated islets and clonal pancreatic b-cells. J. Endocrinol., 2007, 192(1), 159-168.

[33] Frankish, N.; de Sousa, M.F.; Mills, C.; Sheridan, H. Enhancement of insulin release from the beta-cell line INS-1 by an ethanolic extract of Bauhinia variegata and its major constituent roseoside. Planta Med., 2010, 76(10), 995-997.

[34] Ko, B.S.; Choi, S.B.; Park, S.K.; Jang, J.S.; Kim, Y.E.; Park, S. Insulin sensitizing and insulinotropic action of berberine from Cortidis rhizoma. Biol. Pharm. Bull., 2005, 28(8), 1431-1437.

[35] Anand, P.; Murali, Y.K.; Tandon, V.; Murthy, P.S.; Chandra, R. Insulinotropic effect of aqueous extract of Brassica nigra improves glucose homeostasis in streptozotocin induced diabetic rats. Exp. Clin. Endocrinol. Diabetes, 2009, 117(6), 251-256.

[36] Anand, P.; Murali, K.Y.; Tandon, V.; Murthy, P.S.; Chandra, R. Insulinotropic effect of cinnamaldehyde on transcriptional regulation of pyruvate kinase, phosphoenolpyruvate carboxykinase, and GLUT4 translocation in experimental diabetic rats. Chem. Biol. Interact., 2010, 186(1), 72-81.

[37] Maroo, J.; Vasu, V.T.; Gupta, S. Glucose lowering effect of aqueous extract of Enicostemma littorale Blume in diabetes : a possible mechanism of action. J. Ethnopharmacol., 2002, 81(3), 317-320.

[38] Qa, F.; Verspohl, E.J.; Nahrstedt, A.; Petereit, F.; Matalka, K.Z. Cinchonain $\mathrm{lb}$ isolated from Eriobotrya japonica induces insulin secretion in vitro and in vivo. J. Ethnopharmacol., 2009, 124(2), 224-227.

[39] Souza, A.; Mbatchi, B.; Herchuelz, A. Induction of insulin secretion by an aqueous extract of Tabernanhte iboga Baill. (Apocynaceae) in rat pancreatic islets of Langerhans. J. Ethnopharmacol., 2011, 133(3), 1015-1020.

[40] Liu, D.; Zhen, W.; Yang, Z.; Carter, J.D.; Si, H.; Reynolds, K.A. Genistein acutely stimulates insulin secretion in pancreatic betacells through a camp-dependent protein kinase pathway. Diabetes, 2006, 55(4), 1043-1050.

[41] Skyler, J.S. Diabetic complications. The importance of glucose control. Endocrinol. Metab. Clin. North Am., 1996, 25(2), 243-254.

[42] Urooj, A.; Ahmed, F. Ficus racemosa and Morus indica : emerging alternative antihypergl- ycemic agents. Open Conference Pro. $J ., \mathbf{2 0 1 3}, 4,59-65$.

[43] Wan, L.; Chen, C.; Xiao, Z.; Wang, Y.; Min, Q.; Yue, Y.; Chen, J. In vitro and in vivo anti-diabetic activity of Swertia kouitchensis extract. J. Ethnopharmacol., 2013, 147(3), 622-630.

[44] Ai, T.T.M.; Huyen, N.V.C. Anti-hyperglycemic activity of an aqueous extract from flower buds of Cleistocalyx operculatus (Roxb.) Merr and Perry. Biosci. Biotechnol. Biochem., 2007, 71(1), 69-76.

[45] Arunachalam, K.; Parimelazhagan, T. Antidiabetic activity of Ficus amplissima Smith bark extract in streptozotocin induced diabetic rats. J. Ethnopharmacol., 2013, 147(2), 302-310. 
[46] Verma, L.; Khatri, A.; Kaushik, B.; Patil, U.K.; Pawar, R.S. Antidiabetic activity of Cassia occidentalis (Linn) in normal and alloxan-induced diabetic rats. Indian J. Pharmacol., 2010, 42(4), 224-228.

[47] Helena, L.; Demarchi, V.; Fontana, D.; Hunger, H.; Maria, I.; Brighente, C.; Geraldo, M.; Regina, F.; Barreto, M. Antihyperglycemic action of apigenin-6-C- $\beta$-fucopyranoside from Averrhoa carambola. Fitoterapia, 2012, 83(7), 1176-1183.

[48] Sujith, K.; Darwin, R.; Roosewelt, C. Antidiabetic activity of methanolic extract of Butea frondosa leaves with its possible mechanism of action. Asian J. Pharm. Clin. Res., 2011, 4(3), 9398.

[49] Somani, R.; Kasture, S.; Kumar, A. Antidiabetic potential of Butea monosperma in rats. Fitoterapia, 2006, 77(2), 86-90.

[50] Joseph, B.; Jini, D. Antidiabetic effects of Momordica charantia (bitter melon) and its medicinal potency. Asian Pac. J. Trop. Dis., 2013, 3(2), 93-102.

[51] Kumar, E.K.D.; Janardhana, G.R. Antidiabetic activity of alcoholic stem extract of Nervilia plicata in streptozotocin-nicotinamide induced type 2 diabetic rats. J. Ethnopharmacol., 2011, 133(2), 480483.

[52] Chang, C.L.T.; Lin, Y.; Bartolome, A.P.; Chen, Y.; Chiu, S.; Yang, W. Herbal therapies for type 2 diabetes mellitus : Chemistry, biology, and potential application of selected plants and compounds. Evid. Based Complement. Alternat. Med., 2013, 2013.

[53] Rizvi, S.I.; Mishra, N. Traditional Indian medicines used for the management of diabetes mellitus. J. Diabetes Res., 2013, 2013.

[54] Asgary, S. The inhibitory effects of pure flavonoids on in vitro protein glycosylation. J. Herb. Pharmacother., 2002, 2(2), 47-55.

[55] Motomura, K.; Fujiwara, Y.; Kiyota, N.; Tsurushima, K.; Takeya, M.; Nohara, T.; Nagai, R.; Ikeda, T. Astragalosides isolated from the root of Astragalus radix inhibit the formation of advanced glycation end products. J. Agric. Food Chem., 2009, 57(17), 76667672 .

[56] Jung, H.A.; Jung, Y.J.; Yoon, N.Y.; Jeong da, M.; Bae, H.J.; Kim, D.W.; Na, D.H.; Choi, J.S. Inhibitory effects of Nelumbo nucifera leaves on rat lens aldose reductase, advanced glycation endproducts formation, and oxidative stress. Food Chem. Toxicol., 2008, 46(12), 3818-3826.

[57] Joglekar, M.M.; Panaskar, S.N.; Arvindekar, A.U. Inhibition of advanced glycation end product formation by cymene - a common food constituent. J. Funct. Foods, 2014, 6, 107-115.

[58] Martha, R.; Gutierrez, P. Inhibition of advanced glycation endproduct formation by Origanum majorana L. in vitro and in streptozotocin-induced diabetic rats. Evid. Based Complement. Alternat. Med., 2012, 2012, 598638.

[59] Lunceford, N.; Gugliucci, A. Ilex paraguariensis extracts inhibit AGE formation more efficiently than green tea. Fitoterapia, 2005, 76(5), 419-427.

[60] Martineau, L.C.; Cuerrier, A.; Johns, T.; Haddad, P.S.; Bennett, S.A.L. Inhibition of advanced glycation end product formation by medicinal plant extracts correlates with phenolic metabolites and antioxidant activity. Planta Med., 2011, 77(2), 196-204.

[61] Jung, S.H.; Lee, Y.S.; Shim, S.H.; Lee, S.; Shin, K.H.; Kim, J.S.; Kim, Y.S.; Kang, S.S. Inhibitory effects of Ganoderma applanatum on rat lens aldose reductase and sorbitol accumulation in streptozotocin-induced diabetic rat tissues. Phytother. Res., 2005, 19(6), 477-480.

[62] Lee, H.S. Inhibitory activity of Cinnamomum cassia bark-derived component against rat lens aldose reductase. J. Pharm. Pharm. Sci., 2002, 5(3), 226-230.

[63] Suryanarayana, P.; Kumar, P.A.; Saraswat, M.; Petrash, J.M.; Reddy, G.B. Inhibition of aldose reductase by tannoid principles of Emblica officinalis : implications for the prevention of sugar cataract. Mol. Vis., 2004, 10, 148-154.

[64] Dk, P.; Kumar, R.; Kumar, M.; Sairam, K.; Hemalatha, S. Evaluation of in vitro aldose reductase inhibitory potential of different fraction of Hybanthus enneaspermus Linn F. Muell. Asian Pac. J. Trop. Biomed., 2012, 2(2), 134-139.

[65] Hsieh, P.; Huang, G.; Ho, Y.; Lin, Y.; Huang, S.; Chiang, Y.; Tseng, M.; Chang, Y. Activities of antioxidants , $\alpha$-glucosidase inhibitors and aldose reductase inhibitors of the aqueous extracts of four Flemingia species in Taiwan. Bot. Stud., 2010, 51(3), 293-302.

[66] Pathania, S.; Randhawa, V.; Bagler, G. Prospecting for novel plantderived molecules of Rauvolfia serpentina as inhibitors of aldose reductase, a potent drug target for diabetes and its complications. PLoS One, 2013, 8(4), 1-16.

[67] Chethan, S.; Dharmesh, S.M.; Malleshi, N.G. Bioorganic and medicinal chemistry inhibition of aldose reductase from cataracted eye lenses by finger millet (Eleusine coracana) polyphenols. Bioorg. Med. Chem., 2008, 16(23), 10085-10090.

[68] Akileshwaria, C.; Raghua, G.; Muthennaa, N.H.; Muellerb, P.S ; Petrashb, J.M.; Reddy, G.B. Bioflavonoid ellagic acid inhibits aldose reductase: implications for prevention of diabetic complications. J. Funct. Foods, 2013, 6, 374-383.

[69] Goodarzi, M.T.; Zal, F.; Malakooti, M.; Safari, M.R. Inhibitory activity of flavonoids on the lens aldose reductase of healthy and diabetic rats. Acta. Med. Iranica, 2006, 44(1), 41-45.

[70] Haraguchi, H.; Hayashi, R.; Ishizu, T.; Yagi, A. A flavone from Manilkara indica as a specific inhibitor against aldose reductase in vitro. Planta Med., 2003; 69(9), 853-855.

[71] Jung, S.H.; Lee, Y.S.; Lee, S.; Lim, S.S.; Kim, Y.S.; Shin, K.H. Isoflavonoids from the rhizomes of Belamcanda chinensis and their effects on aldose reductase and sorbitol accumulation in streptozotocin induced diabetic rat tissues. Arch. Pharm. Res., 2002, 25(3), 306-312.

[72] Shin, K.H.; Kang, S.S.; Seo, E.A.; Shin, S.W. Isolation of aldose reductase inhibitors from the flowers of Chrysanthemum boreale. Arch. Pharm. Res., 1995, 18(2), 65-68.

[73] Lee, H.S. Rat lens aldose reductase inhibitory activities of Coptis japonica root-derived isoquinoline alkaloids. J. Agric. Food Chem., 2002, 50(24), 7013-7016.

[74] Lee, H.S. Cuminaldehyde: Aldose reductase and alpha-glucosidase inhibitor derived from Cuminum cyminum L. seeds. J. Agric. Food Chem., 2005, 53(7), 2446-2450.

[75] Zhang, L.; Dai, S.; Nie, X.; Zhu, L.; Xing, F.; Wang, L. Effect of Salvia miltiorrhiza on retinopathy. Asian Pac. J. Trop. Med., 2013, 6(2), 145-149.

[76] Liang, X.; Hagino, N.; Guo, S.; Tsutsumi, T.; Kobayashi, S. Therapeutic efficacy of Stephania tetrandra S. Moore for treatment of neovascularization of retinal capillary (retinopathy) in diabetes - in vitro study. Phytomedicine, 2002, 9(5), 377-384.

[77] Chan, H.; Chang, R.C.; Ip, A.K.; Chiu, K.; Yuen, W.; Zee, S.; So, K. Neuroprotective effects of Lycium barbarum Lynn on protecting retinal ganglion cells in an ocular hypertension model of glaucoma. Exp. Neur., 2007, 203(1), 269-273.

[78] Chiu, K.; Chan, H.; Yeung, S. Modulation of microglia by Wolfberry on the survival of retinal ganglion cells in a rat ocular hypertension model. J. Ocul. Biol. Dis. Infor., 2009, 2(2), 47-56.

[79] Huang, S.; Jeng, C.; Kao, S.; Yu, J.J. Improved haemorrheological properties by Ginkgo biloba extract (Egb 761) in type 2 diabetes mellitus complicated with retinopathy. Clin. Nutr., 2004, 23(4), 615-621.

[80] Higuchi, A.; Yamada, H.; Yamada, E.; Jo, N.; Matsumura, M. Hypericin inhibits pathological retinal neovascularisation in a mouse model of oxygen-induced retinopathy. Mol. Vis., 2008, 14, 249-254.

[81] Huang, W.; Li, G.; Qiu, J.; Gonzalez, P.; Challa, P. Protective Effects of Resveratrol in Experimental Retinal Detachment. PLoS One, 2013, 8(9), 1-7.

[82] Bursell, S.E.; Clermont, A.C.; Aiello, L.P.; Aiello, L.M.; Schlossman, D.K.; Feener, E.P.; Laffel, L.; King, G.L. High dose vitamin E supplementation normalizes retinal blood flow and creatinine clearance in patients with type 1 diabetes. Diabetes Care, 1999, 22(8), 1245-1251.

[83] Carter, C.A.; Kane, C.J. Therapeutic potential of natural compounds that regulate the activity of protein kinase C. Curr. Med. Chem., 2004, 11(21), 2883-2902.

[84] Aradkar, P.; Dubey, P.; Krishna, M.; Verma, N.J. Modulation of radiation-induced protein kinase $\mathrm{C}$ activity by phenolics. Radiol. Prot., 2001, 21(4), 361-370.

[85] Balasubramanyam, M.; Koteswari, A.A.; Kumar, R.S.; Monickaraj, S.F.; Maheswari, J.U.; Mohan, V. Curcumin-induced inhibition of cellular reactive oxygen species generation: novel therapeutic implications. J. Biosci., 2003, 28(6), 715-721.

[86] Kowluru, R.A.; Kanwar, M. Effects of curcumin on retinal oxidative stress and inflammation in diabetes. Nutr. Metab., 2007, 4, 8

[87] Sabu, M.C.; Smitha, K.; Kuttan, R. Anti-diabetic activity of green tea polyphenols and their role in reducing oxidative stress in experimental diabetes. J. Ethnopharmacol., 2002, 83(1-2), 109-116. 
[88] Mustata, G.T.; Rosca, M.; Biemel, K.M.; Reihl, O.; Smith, M.A.; Viswanathan, A.; Strauch, C.; Du, Y.; Tang, J.; Kern, T.S.; Lederer, M.O.; Brownlee, M.; Weiss, M.F.; Monnier, V.M. Paradoxical effects of green tea (Camellia sinensis) and antioxidant vitamins in diabetic rats: Improved retinopathy and renal mitochondrial defects but deterioration of collagen matrix glycoxidation and cross-linking. Diabetes, 2005, 54(2), 517-526.

[89] Toolsee, N.A.; Aruoma, O.I.; Gunness, T.K.; Kowlessur, S.; Dambala, V.; Murad, F.; Googoolye, K.; Daus, D.; Indelicato, J.; Rondeau, P.; Bourdon, E.; Bahorun, T. Effectiveness of green tea in a randomized human cohort: relevance to diabetes and its complications. Biomed. Res. Int., 2013, 2013.

[90] Al-Azzawie, H.F.; Alhamdani, M.S.S. Hypoglycemic and antioxidant effect of oleuropein in alloxan-diabetic rabbits. Life Sci., 2006, 78(12), 1371-1377.

[91] Hamden, K.; Allouche, N.; Damak, M.; Elfeki, A. Hypoglycemic and antioxidant effects of phenolic extracts and purified hydroxytyrosol from olive mill waste in vitro and in rats. Chem. Biol. Interact., 2009, 180(3), 421-432.

[92] Dong, L.Y.; Jin, J.; Lu, G.; Kang, X.L. Astaxanthin attenuates the apoptosis of retinal ganglion cells in $\mathrm{db} / \mathrm{db}$ mice by inhibition of oxidative stress. Mar. Drugs, 2013, 11(3), 960-974.

[93] Obrosova, I.G.; Fathallah, L.; Greene, D.A. Early changes in lipid peroxidation and antioxidative defense in diabetic rat retina: effect of DL-alpha-lipoic acid. Eur. J. Pharmacol., 2000, 398(1), 139-46.

[94] Liang, B.; Guo, Z.; Xie, F.; Zhao, A. Antihyperglycemic and antihyperlipidemic activities of aqueous extract of Hericium erinaceus in experimental diabetic rats. BMC Complem. Altern. M., 2013, 13(253), 1-7.

[95] Cho, W.C.S.; Chung, W.S.; Lee, S.K.W.; Leung, A.W.N.; Cheng, C.H.K.; Yue, K.K. M. Ginsenoside Re of Panax ginseng possesses significant antioxidant and antihyperlipidemic efficacies in streptozotocin-induced diabetic rats. Eur. J. Pharmacol., 2006, 550(1-3), 173-179.

[96] Maher, P.; Hanneken, A. Flavonoids protect retinal ganglion cells from oxidative stress-induced death. Invest. Ophthalmol. Vis. Sci., 2005, 46(12), 4796-803.

[97] Gamet-Payrastre, L.; Manenti, S.; Gratacap, M.P.; Tulliez, J.; Chap, H.; Payrastre, B. Flavonoids and the inhibition of PKC and PI 3-kinase. Gen. Pharmacol., 1999, 32(3), 279-286.

[98] Agrawal, S.S.; Naqvi, S.; Gupta, S.K.; Srivastava, S. Prevention and management of diabetic retinopathy in STZ diabetic rats by $T i-$ nospora cordifolia and its molecular mechanisms. Food Chem. Toxicol., 2012, 50(9), 3126-3132.

[99] Gupta, S.K.; Kumar, B.; Srinivasan, B.P.; Nag, T.C.; Srivastava, S.; Saxena, R.; Aggarwal, A. Retinoprotective effects of Moringa oleifera via antioxidant, anti-inflammatory, and anti-angiogenic mechanisms in streptozotocin-induced diabetic rats. J. Occul. Pharmacol. Ther., 2013, 29(4), 419-426.

[100] Abdul, L.; Abdul, R.; Sukul, R.R.; Siddiqui, N. Anti-inflammatory and Antihistaminic Study of a Unani Eye Drop Formulation. Ophthalmol. Eye Dis., 2010, 2, 17-22.

(c) Pandita and Vaidya; Licensee Bentham Open

This is an open access article licensed under the terms of the Creative Commons Attribution Non-Commercial License (http://creativecommons.org/licenses/by-nc/3.0/) which permits unrestricted, non-commercial use, distribution and reproduction in any medium, provided the work is properly cited. 